\title{
NEW VISCOSE RESEARCH LABORATORY OF COURTAULDS, LTD.
}

$\mathrm{T}$ HE new viscose research laboratory of Courtaulds, Ltd., has recently been completed at Coventry and was on view to visitors during the week commencing May 16. This is the latest, and at present the largest, of the Company's six research laboratories. Together with its associated pilot plants, the laboratory will be devoted almost entirely to research and development work on the manufacture of regenerated cellulose fibres by the viscose process. Broadly speaking, its main objects are to effect major improvements in the properties of the fibre and to develop improved methods of manufacture. Its activities will range from fundamental to large-scale technological work in a broadly based programme.

The man-made fibre industry operates to-day on a very large scale; it is not generally realized that it supplies nearly 20 per cent of the world's textile requirements. Of its annual world output of some two million tons, about 80 per cent is produced by the viscose process. Originally the only product of this process was continuous-filament textile yarn. The viscose process has, however, proved remarkably flexible; the range of its products has progressively widened, and to-day includes special high-tenacity yarns used mainly for industrial purposes and a number of different types of staple fibre. With the expanding range of outlets, a host of new problems has arisen in developing fibres specially suited to particular end uses.

The raw material of the industry is cellulose, predominantly in the form of highly refined wood pulp. It is abundant and relatively cheap, as are the other major chemicals employed. The industry is therefore in a position to expand its output to keep pace with the world's ever-increasing demand for textiles.

The processes involved in the production on an industrial scale of regenerated cellulose fibres with properties suited to their various uses are complex and inherently difficult to investigate; even after fifty years of activity the industry still presents many problems of considerable depth which remain to be solved. In the early days, considerable progress was made despite the lack of understanding of the background science; but the time has now come when progress will depend increasingly on a thorough understanding of the physical and chemical changes which take place during the production of the viscose solution, its extrusion into a coagulating bath and the subsequent regeneration of cellulose in the form of filaments with properties suited to their end use. A major aim of the new research laboratory will be to provide this essential background.

In the field of textile science it is not yet possible to describe satisfactorily in terms of measurable parameters many of the properties of fabrics such as drape, handle or durability, which control both their functional behaviour and their appeal to the customer. It remains also to relate these textile properties in a satisfactory manner both to the details of fabric construction and to the properties of the fibres from which they are made. The man-made fibre industry has always striven to produce fibres with the most useful properties, and, for an intelligent approach to this problem, it is necessary to relate these properties to the ehemical nature of the building unit-the linear polymer molecule-and to the fine structure and morphology of the fibre. Only by the fundamental study of these problems can technological progress be firmly based, and the work of the individual sections of the new laboratory is integrated with these general aims in view.

The raw material, wood pulp, is being studied in relation to its subsequent behaviour in the viscose process and to the properties of the ultimate fibre. Some of this work is carried out in collaboration with pulp producers, and it is an interesting example of the power of co-operative effort that it has already produced useful results in a difficult field of investigation.

The extrusion or spinning of viscose solution through the fine holes of a spinnerette into an acid coagulant produces filaments of regenerated cellulose by a variety of chemical and physical processes which occur with great rapidity. Persistent physicochemical study is slowly clarifying the picture; but the basic research tool is undoubtedly the single-end spinning machine. Direct investigation of spinning phenomena based upon the indications of more fundamental work yields positive information about the physical and chemical conditions which control the formation and properties of the filament. Every attempt is made to build the necessary basic properties of strength, flexibility and elasticity into the fibre. In addition it is possible, by the incorporation of extremely fine dispersions of white or coloured pigments into the viscose solution, to modify the lustre of the yarn and to produce a wide range of extremely fast colours. This latter development is particularly important in the field of staple fibre where many of the end uses call for extreme colour fastness and where additional effects can readily be obtained by blending fibres of different colours.

The properties of regenerated cellulose fibres can also be modified by chemical after-treatment. This is very largely the province of the organic chemist who is able to control the degree of swelling in water by means of cross-linking reactions, to confer water repellency, the power of adhesion to rubber and many other specific properties by the use of suitable reagents.

In order to facilitate the rapid utilization of research results in production, the laboratory is associated with extensive pilot plants and has a large engineering section.

The new building, which is steel-framed with floors and roof of pre-cast concrete beams, consists of a basement and four floors of laboratories in the main block. An office wing links it to an existing administrative block. The 'Cotswold grey' brick façade overlooking the main Foleshill Road contrasts with the extensive glass area of the laboratory windows on the other three sides of the building, and insulates the working areas from street noises; at the same time a maximum amount of light reaches the working areas.

On each floor the laboratories are situated on both sides of a central corridor. They are based on a standard module of $25 \mathrm{ft} .6 \mathrm{in.} \times 11 \mathrm{ft} .9 \mathrm{in}$. Pro- 
vision is made for supplying all services to every module so that the internal layout can readily be modified to suit changing requirements. 'The services are distributed by horizontal mains running at high level throughout the basement, with branches rising up vertical ducts on each side of the central corridor. From these vertical risers branch-pipes are taken through shallow floor-ducts to the laboratory benches. The services include high-and low-pressure steam; electrical power ; cold, hot and demineralized water; coal gas; compressed air and vacuum; and brine for cooling. The building is heated and ventilated by warmed and filtered air distributed from a plant in the basement by a plenum system which is directed into three zones per floor; each zone has a subsidiary heater which is under local thermostatic control. Special air-conditioning is provided for the textile research and testing laboratories where constant temperature and humidity conditions are required.

The new laboratory was designed by the Company's architects and engineers in consultation with the scientific staff and completes the post-war development of Courtaulds' viscose research facilities. Major extensions of the Company's other laboratories are in progress.

\section{MICROWAVE AND RADIO- FREQUENCY SPECTROSCOPY}

\section{FARADAY SOCIETY MEETING}

\section{A} THREE-DAY meeting of the Faraday Society was held in Cambridge during April 4-6, when the subject of the discussion was "Microwave and Radio-frequency Spectroscopy". The president, Prof. R. G. W. Norrish, opened the meeting, at which more than two hundred members were present, by welcoming more than a hundred British and foreign guests; these included contributors from Denmark, France, Germany, the Netherlands, Switzerland, the United States and the U.S.S.R.

Ten years ago the subject of microwave and radiofrequency spectroscopy embraced essentially only one experiment, namely the direct detection of the inversion frequency of ammonia by C. E. Cleeton and N. H. Williams. Consequently, the majority of members of the Society were not taught anything about low-frequency spectroscopy during their student days. Since the techniques involve a considerable amount of advanced physics and electronic engineering, most members had not had an opportunity of gaining first-hand experience and, as a consequence, were very glad of the opportunity of leaming directly from the pioneers and of judging for themselves the possible applications of the new techniques to their own individual interests. They learned that a wide range of topies was concealed under the narrow-sounding title, and there were important contributions to the following subjects: chemical structures, geometrical structures of molecules, electronic structures, thermodynamics, equilibria, molecular kinetics, electrochemical kinetics, botany, biology and astronomy.

In the formal sessions, thirty papers were presented and discussed. Since a summary which would do full justice to these would either be very lengthy or would assume the reader to possess a detailed background knowledge, the rest of this article will enumerate the results presented without detailed reference to the manner in which they were obtained. Besides the original work, there were several contributions which were wholly, or in part, of an introductory or review nature. In the latter class were the accounts of nuclear properties (H. C. Longuet-Higgins), microwave or pure rotation gas spectroscopy (W. D. Gwinn; W. Gordy), non-resonant electron absorption in flames (T. M. Sugden), paramagnetic electron resonance in compounds with metal ions (J.H. E. Griffiths), free radical electron resonance (G. E. Pake), nuclear magnetic resonance (H. S. Gutowsky), and quadrupole resonance in solids (H. G. Dehmelt).

\section{Chemical Structure}

When presented with any material, a chemist's primary task is to determine the structural formula. The structure of diketene has been established to be

$$
\begin{aligned}
\mathrm{CH}_{2}= & \mathrm{C}-\mathrm{CH}_{2} \\
! & ! \\
\mathrm{O} & -\mathrm{C}=\mathrm{O}
\end{aligned}
$$

by P. T. Ford and R. E. Richards from the proton resonance of the solid, and this has been confirmed. by entirely distinct evidence, from the chemical shifts in the liquid, presented by H. S. Gutowsky. The latter type of experiment is relatively rapid and easy to interpret qualitatively, and already a table of characteristic shifts has been established and is likely to have many applications analogous to those of a table of characteristic infra-red absorption frequencies. Also, elegant proofs of the correctness of the bridge structures for diborane, for the pentaborane pyramid, and for the decarborane basket, were given by J. N. Shoolery using the nuclear 'double resonance' technique. A rather different identification of a structural unit is that of E. E. Schneider, who used the electron resonance of the free radicals obtained by the degradation of polymers by irradiation with $\mathrm{X}$-rays; with polythene the evidence points to predominantly - $\mathrm{CH}_{2}^{\prime}$ and with 'Teflon' to - $\mathrm{CF}_{2}^{\circ}$ ends to the free radical chains. Another experiment is that of R. R. Livingston et al., who identified hydrogen atoms trapped in phosphoric acid, sulphuric acid and perchloric acid on irradiation with $\gamma$-rays at $77^{\circ} \mathrm{K}$.

\section{Geometrical Structure}

For compounds of established chemical structures, a chemist is interested to discover the geometrical structure, that is the bond distances and angles, and microwave gas spectroscopy is a powerful tool for this purpose. W. D. Gwinn reported that trimethylene oxide,

$$
\begin{aligned}
& \mathrm{CH}_{2}-\mathrm{CH}_{2} \\
& \mathrm{CH}_{2}-\mathrm{O}
\end{aligned}
$$

has a strictly planar central skeleton. J. Sheridan et al., reporting the dimensions of methyl diacetylene, found the $\mathrm{CH}_{3}-\mathrm{C}$ bond to be $1.46 \mathrm{~A}$. and the central single bond between the two triple bonds to be $1 \cdot 37$ A., and these figures show a marked shortening with respect to the C-C bond in ethane, which is $1.54 \mathrm{~A}$. Another short $\mathrm{C}-\mathrm{C}$ bond is that reported by $\mathrm{B}$. Bak et al., who found $1.44 \mathrm{~A}$. for the $\mathrm{C}_{(3)}-\mathrm{C}_{(4)}$ bond in furan. Nuclear resonance can be uscd for locating hydrogen atoms, and E. R. Andrew and D. Hyndman have used it for showing that in the solid state the hydrogen atoms of urea lie in the $\mathrm{CON}_{2}$ plane. The accuracy of the method is shown by the results of 